\title{
Does the Presence of Impacted Mandibular Third Molars Increase the Risk of Bad Split Incidence During Bilateral Sagittal Split Osteotomy?
}

\author{
Majid Eshghpour ${ }^{1}$, Ali Labafchi ${ }^{2}$, Sahand Samieirad ${ }^{3} *$, Majid Hosseini Abrishami ${ }^{1}$, Elham \\ Nodehi $^{2}$, Abdollah Rashid Javan 4
}

1. Oral and Maxillofacial Diseases Research Center, Mashhad University of Medical Sciences, Mashhad, Iran;

2. Student Research Committee, Faculty of Dentistry, Mashhad University of Medical Sciences, Mashhad, Iran;

3. Department of Oral \& Maxillofacial Surgery, Mashhad Dental School, Mashhad University of Medical Sciences, Mashhad, Iran;

4. Department of Biostatistics, Mashhad University of Medical Sciences, Mashhad, Iran.

\footnotetext{
*Corresponding Author:

Sahand Samieirad,

Associate Professor of Oral \& Maxillofacial surgery department, Mashhad dental school, Mashhad University of Medical Sciences, Mashhad, Iran.
}

Tel: $+98-51-38829501-15$

Fax: +98-51-38829500

Email: samieerads@mums.ac.ir

Received: January 10, 2020

Revised: July 28, 2020

Accepted: August 9, 2020

\section{ABSTRAC1}

\section{BACKGROUND}

The possibility of mandibular bad spilt might happen during bilateral sagittal split osteotomy (BSSO). This study investigated the effect of impacted mandibular third molars on bad spilt incidence during BSSO.

\section{METHODS}

Totally, 140 patients under 40 years old who were candidates for BSSO surgery due to class 3 skeletal discrepancy were divided randomly into two equal groups. The impacted mandibular third molars were presented in one group during BSSO (Exposed), and the third molars were removed at least six months before surgery for the other group (Unexposed). All cases underwent BSSO using the same technique by a single surgeon. A bad split was diagnosed by inter-operative clinical examination and postoperative panoramic radiography.

\section{RESULTS}

Four bad split occurrences were observed including three patients in the group which impacted mandibular third molars were presented and one patient in the group without impacted mandibular third molars. The incidence of bad fracture in the exposed group was 3.7 times more than the unexposed group. The incidence of the bad fracture in exposed group was 3.7 times more than unexposed group. The chance of fractures in females was 1.7 times higher than males. With one year addition to the patient's age, chance of fracture increased 0.985 times more.

\section{CONCLUSION}

Overall incidence of bad split fracture in presence of mandibular third molars in females and at older ages increased during BSSO. The extraction of impacted mandibular third molars, six months before the BSSO is recommended to prevent the bad split incidence during the operation.

\section{KEYWORDS}

Mandibular impacted third molar; Bilateral sagittal split osteotomy; Bad split

Please cite this paper as:

Eshghpour M, Labafchi A, Samieirad S, Hosseini Abrishami M, Nodehi E, Rashid Javan A. Does the Presence of Impacted Mandibular Third Molars Increase the Risk of Bad Split Incidence During Bilateral Sagittal Split Osteotomy? World J Plast Surg.2021;10(1):37-42. doi: 10.29252/wjps.10.1.37

\section{INTRODUCTION}

One of the most common maxillofacial surgeries for the correction of dentofacial deformities is bilateral sagittal split osteotomy (BSSO). ${ }^{1,2}$ Trauner and Obwegeser ${ }^{3}$ originally introduced this technique, and it was modified by Hunsuck, ${ }^{4}$ Dalpont, ${ }^{5}$ and Epker ${ }^{6}$ to limit the postoperative complications. Despite these efforts, this technique remains challenging in some cases. ${ }^{7-9}$ 
Several studies have documented BSSO-related complications, including arterial bleeding, unfavorable fractures pattern termed 'bad split'; proximal segment malposition, necrosis of surgical site, as well as, condylar and temporomandibular joint disorders. ${ }^{1,2,9,10}$

Bad split is an irregular fracture of the mandible in an inappropriate location during osteotomy. ${ }^{7,9,11}$ In other words, the bone fracture occurs at the buccal (proximal) or lingual (distal) cortical plate, at the coronoid process, or the condylar neck, rather than splitting into the sagittal section. ${ }^{7,10-12}$ Recent studies reported that the incidence of bad splits during BSSO ranged from $0.2 \%$ to $14.6 \% .^{12,13}$ This unfavorable split pattern may delay bone healing, infections, and the sequestration of bony fragments. ${ }^{1}$ Also, instability or mandible dysfunction can lead to long term complications as well as temporomandibular joint dysfunction. ${ }^{1,9}$

Various risk factors for the bad fracture have been reported, including inappropriate quality and quantity of bone, presence of impacted third molar, surgeon error during the operation, and incorrect usage of osteotomy instrument. ${ }^{1,12,13}$ In human beings, the third mandibular molar is the most frequently observed impacted teeth. ${ }^{14}$ Different studies have reported a different prevalence of impacts ranging from $16.7 \%$ to $68.6 \% .^{1,14,15}$ The review of the literature revealed that few studies have examined the association between the bad split occurrence and the presence of the impacted third mandibular molar. ${ }^{1,2,8,9,16}$

Some studies have indicated that impacted molars can decrease bone quantity in the surgical site, especially at the mandibular angle, and may increase the risk of bad split. ${ }^{1,9,17}$ Therefore, it is recommended that the third molars to be extracted at least six months before BSSO surgery. ${ }^{9}$ However, the controversy regarding this issue exists. ${ }^{10,11}$ The aim of this prospective study was to investigate the association between third molars status and bad split occurrence during BSSO surgery.

\section{MATERIALS AND METHODS}

The protocol of this prospective cohort study was confirmed by the Ethics and Research Committee of Mashhad University of Medical Sciences (IR.MUMS.DENTISTRY.REC.1397.049). The guidelines of the STROBE (Strengthening the Reporting of Observational Studies in Epidemiology), as well as the principles of the Helsinki Declaration, were followed in this research. Informed written consent was collected from all participants before enrollment. This observational research was conducted from September 2017 to August 2019 in our Department of Maxillofacial Surgery.

After obtaining informed consent, all healthy (ASA I, II) nonsmoker patients with skeletal class III deformity aged over 18 years, who were candidates for either monomax or bimaxillary orthognathic surgery with BSSO technique were included in this study. All individuals had bilateral impacted third molars. Patients with a history of maxillofacial trauma were excluded. Other exclusion criteria were severe medical conditions (ASA $\geq$ III) as well as those who declined follow-up examinations.

All participants were randomly divided into two equal groups. In the exposed group, the impacted third mandibular molars existed during BSSO. The impacted third mandibular molars were removed six months before the operation, in the unexposed group. A detailed history, pre-operative evaluations, and routine laboratory, and radiographic examinations (OPG) were performed for each case. For each patient, the probability of bad splits incidence due to the existence of impacted third molars during the operation was clarified. Hence, patients were allowed to choose whether to be removed at least six months before surgery or impacted molars to be removed during surgery.

All surgeries were carried out at the same hospital by a single surgeon, using the Epker modification with sagittal splitters and separators. ${ }^{6}$ Patients were continued on nothing by mouth (NPO) for 8 hours, preoperatively. All patients were given the same intravenous standard medications for general hypotensive anesthesia. The cases were monitored via pulse oximetry device, electrocardiograph and thermal probe, as well as the capnography device. In addition, all vital signs including heart rate (HR) and mean arterial pressure (MAP) during surgery were controlled to avoid intraoperative complications.

Patients underwent orthognathic setback surgery with the Epker BSSO technique. Moreover, the impacted tooth did not affect the osteotomy plan. If the impacted tooth were loosened or cut after splitting, it would be extracted. The mandibular segments were rigidly fixed, with two bilateral lag screws. In case of a bad split, in addition to screws, 
a mini-plate was also used. Preventing any potential infection, all subjects received intravenous cefazolin antibiotic therapy. Additionally, intravenous dexamethasone was administered in all patients; to minimize edema, inflammation, and pain. All patients were asked to come back for follow-up 1, 3, and 6 months after the operation.

The presence or absence of impacted third molars and the occurrence of the bad splitting were the independent variables. Also, BSSO surgery was the dependent variable. Furthermore, the age and gender of each patient were recorded. A bad split was described as an unfavorable fracture pattern in the lingual (distal) or buccal (proximal) part of the mandible, which occurred after osteotomy and diagnosis by inter-operative clinical examination and postoperative panoramic radiography. It should be noted that the bad split was recorded, whether occurred or not occurred. To confirm the diagnosis of the possible fractures that were not identified during the surgery, examination via panoramic radiographs was performed. Finally, the data results were reviewed and forwarded to the statistical expert.

The statistical analysis was performed using SPSS software (version 20, SPSS Inc., Chicago, IL, USA). Qualitative data were expressed as percentages, while quantitative variables were stated as mean \pm SD (standard deviation). We used the Chi-Square test, Mann-Whitney test, and Spearman correlation coefficient as well as Fisher's Exact test. The statistically $\mathrm{P}$ value $<0.05$ was considered significant. Logistic regression models which were calibrated for gender and age were used to demonstrate the relation of the presence of impacted mandibular third molars with the risk of a bad fracture incidence.

\section{RESULTS}

In this study, 140 patients, including 88 females $(62.9 \%)$ and 52 males $(37.1 \%)$ were enrolled. The patients' age ranged from 18 to 39 years, with a mean of $24.4 \pm 3.95$ years. All participants were divided into two equal groups. In the exposed group, the impacted mandibular third molars were present, and in the unexposed group, they were absent. There were 44 females and 26 males in both groups and there was no difference between the two groups based on Chi-Square results $(p=1.00)$. The mean age of the exposed group was $23.5 \pm 3.55$ years, and the mean age of the unexposed group was 24.59 \pm 3.65 years. The Mann-Whitney $U$ test demonstrated that the difference was not significant between the two groups $(p=0.166)$. A bad split occurred in three patients $(4.6 \%)$ in the exposed group and one patient $(1.4 \%)$ in the unexposed (Table 1).

Table 1: Bad split incidence among groups with or without Mandibular third molars.

\begin{tabular}{lllll}
\hline Variable & & $\begin{array}{l}\text { Bad split incidence } \\
\text { Negative }\end{array}$ & $\begin{array}{l}\text { Positive } \\
\text { N (\%) }\end{array}$ & $\begin{array}{c}\text { Total } \\
\text { N (\%) }\end{array}$ \\
\hline Groups & & $\mathbf{N}(\%)$ & 3 & $70(50)$ \\
& Exposed & 67 & 1 & $70(50)$ \\
& Unexposed & 69 & $4(2.8)$ & $140(100)$ \\
& Total & $136(97.2)$ & & \\
$\begin{array}{l}p \text { value* } \\
\text { *Fisher's exact test }\end{array}$ & $\mathrm{N}(\%)$ & $p=0.620$ & & \\
\hline
\end{tabular}

Totally, two fractures occurred in the lingual plate, one fracture happened in both lingual and buccal plates, and one bad split arose in the buccal plate, in the present study. This was not a common incidence during BSSO in our 140 cases $(4 / 140=2.86 \%)$. It is worth mentioning that bilateral bad splits did occur in none of the cases. In the exposed group, two fractures occurred in the lingual (distal) plate, and one fracture occurred in both lingual and buccal (proximal) plates. By the way, in the unexposed group, the only bad split occurred in the buccal plate (Table 2).

There was no significant difference between the two groups in terms of bad fracture and region $(p=0.62$ and $p=0.50$, respectively). The variables including group (exposed or unexposed), gender and age entered the logistic regression models to predict the occurrence of the bad fracture. The model was generally significant $(p=0.019)$, and its prediction accuracy was $97.1 \%$. However, variables did not influ- 
ence the incidence of bad splits significantly. Moreover, the presence of a wisdom tooth increased the risk of a bad split by 3.7 times (OR, 3.68; 95\% CI, $0.35-38.67 ; p=0.277)$. Females were 1.7 times more likely to experience a bad split than males (OR,
1.67; 95\% CI, 0.16-17.6; $p=0.669)$. The results demonstrated that, as each year was added to age, the risk of bad fracture incidence increased 0.985 times (OR, 1.133; 95\% CI, 0.88-1.45; $p=0.321$ ) (Table 3).

Table 2: The region of bad split incidence among groups.

\begin{tabular}{lccccc}
\hline & & \multicolumn{3}{c}{ Region of bad split incidence } \\
& & $\begin{array}{c}\text { Lingual plate } \\
\text { Buccal } \\
\text { plate }\end{array}$ & $\begin{array}{c}\text { Lingual and } \\
\text { buccal plates } \\
\mathbf{N}(\%)\end{array}$ & $\begin{array}{c}\text { Total } \\
\mathbf{N}(\%)\end{array}$ \\
\hline Groups & Exposed & 2 & 0 & 1 & $3(75)$ \\
& $\begin{array}{c}\text { Unexposed } \\
\text { Total }\end{array}$ & 0 & 1 & 0 & $1(25)$ \\
& $\mathrm{N}(\%)$ & $2(50)$ & $1(25)$ & $1(25)$ & $4(100)$ \\
& & $p=0.5$ & & & \\
$\begin{array}{l}p \text { value* } \\
\text { *Fisher's exact test }\end{array}$ & & & & & \\
\hline
\end{tabular}

Table 3: Logistic regression analysis of bad split variables.

\begin{tabular}{|c|c|c|c|c|c|c|}
\hline \multirow[t]{2}{*}{ Risk factor } & \multirow{2}{*}{$\begin{array}{l}\text { Regression } \\
\text { coefficient }\end{array}$} & \multirow{2}{*}{$\begin{array}{l}\text { Standard } \\
\text { error }\end{array}$} & \multirow[t]{2}{*}{$P$ value } & \multirow{2}{*}{$\begin{array}{l}\text { Odds ratios } \\
\text { (OR) }\end{array}$} & \multicolumn{2}{|c|}{$95 \%$ CI of OR } \\
\hline & & & & & Lower & Upper \\
\hline Groups & 1.30 & 1.199 & 0.277 & 3.685 & 0.35 & 38.67 \\
\hline Ref*=Exposed & & & & & & \\
\hline Gender & 0.513 & 1.202 & 0.669 & 1.670 & 0.16 & 17.60 \\
\hline Ref $*=$ Female & & & & & & \\
\hline Age & 0.125 & 0.126 & 0.321 & 1.133 & 0.88 & 1.45 \\
\hline Constant & -9.198 & 3.931 & 0.019 & 0.0001 & - & - \\
\hline$*$ Ref $=$ Reference & & & & & & \\
\hline
\end{tabular}

\section{DISCUSSION}

This study investigated the association between the presence of impacted third mandibular molars and bad split occurrence during BSSO surgery. One of the intraoperative complications of BSSO is a bad split fracture, which means bone fractures in other surgery regions rather than splitting into the sagittal section. ${ }^{11}$ On the other hand, the presence of an impacted mandibular third molar in the jaw angle reduces the bone quantity, and it may increase the risk of bad split occurrence. . $^{1,9,10,12,13,18}$

Regarding this fact, some authors suggested that the mandibular wisdom teeth should be removed at least six months preoperatively. ${ }^{9,12}$ However, other authors concluded that the intraoperative mandibular third molar removal minimizes postoperative complications. ${ }^{1}$ Moreover, the correlation between depth and angulation of impacted mandibular third molar and the occurrence of the bad split remained controversial. ${ }^{19} \mathrm{We}$ observed that the presence of impacted mandibular third molars during BSSO surgery increased 3.7 times the chance of bad splits incidence. This result was in line with Camargo et al., ${ }^{8}$ Verveij et al., ${ }^{12}$ and Reyneke et $a l .{ }^{20}$ findings.

Additionally, Mensink et al. found a significant correlation between the intraoperative removal of mandibular third molar and the incidence of bad splits. ${ }^{9}$ However, a meta-analysis done by Steenen et al. ${ }^{1}$ stated that there was no evidence that the presence of wisdom tooth, as well as the patient's age, increased the risk of bad split. Doucet et al. also revealed no correlation between the presence of mandibular third molar and the bad splits incidence. ${ }^{21}$ Nevertheless, several earlier studies have shown that the surgeon's experience and surgical accuracy were the risk factors that might influence the incidence of bad fracture. , $^{922,23}$

In our study, age and gender had minimal and insignificant effects on the bad split incidence; however, older age and female gender had a higher risk for the bad split occurrence. One possible reason might be that in the older ages, the bone 
density increases, and osteotomy becomes more difficult and complicated. Moreover, the anatomical weakness of the mandible in females justifies a higher risk of fractures in this gender. In addition, these two variables (age and gender), as mentioned by Reyneke et al. ${ }^{20}$ and Mehra et al.,${ }^{17}$ did not have a significant effect on the bad split incidence. In consistent with this finding, Kriwalsky et al. described aging as a risk factor for incidence of bad splits without a third molar removal association. ${ }^{11}$

Nevertheless, our BSSO candidate patients were younger than Kriwalsky et al.'s ${ }^{11}$ study (24.4 years compared to 35 years). Totally in the present study, two fractures occurred in the lingual plate, one fracture happened in both lingual and buccal plates, and one bad split arose in the buccal plate. This was not a common incidence during BSSO in our 140 cases $(2.86 \%)$. Preventing bad splits is still a challenging issue. ${ }^{13}$ According to literature, the appropriate design of osteotomy, removal of sharp angles, completion of sufficient cuts along the lower border of the mandible, and careful separation of segments are the best prevention techniques. ${ }^{13}$

Finally, due to the higher possibility of unfavorable fractures during BSSO surgery in patients with impacted mandibular third molars, which has been confirmed in the present study (the presence of impacted mandibular third molars increased the risk of bad split incidence by 3.7 times), it is recommended that the impacted mandibular third molars might be better to remove six months before the BSSO surgery. The limitations of this study are needed to be acknowledged too. Firstly, Due to the design of the study, randomization was not possible. Secondly, due to the impossibility of blinding the surgeon in the study, the surgeon may be more careful during osteotomy in the presence of impacted mandibular third molar, which could cause bias in the results. It is recommended that further studies with a larger sample size to be conducted so that the relationship between study variables to be represented.

\section{CONCLUSION}

Based on our findings, the overall incidence of bad split fracture in the presence of mandibular third molars, in females, and at older ages increased during BSSO. The presence of impacted mandibular third molars increased the risk of bad split incidence by 3.7 times. According to this fact, the authors recommended the extraction of impacted mandibular third molars six months before the BSSO to prevent the bad split incidence during the operation.

\section{ACKNOWLEDGMENTS}

This manuscript is a research project supported by the Research Council of Mashhad University of Medical Sciences, Mashhad, Iran (Thesis NO: 970174). Also, the authors would like to appreciate the continued support of Student Research Committee of Mashhad University of Medical Sciences, Mashhad, Iran. The authors express their gratitude to Dr. Maryam Khorasanchi for her cooperation. This study was self-funded.

\section{CONFLICTS OF INTEREST}

The author has no conflicts of interest to declare.

\section{REFERENCES}

1 Steenen SA, Becking AG. Bad splits in bilateral sagittal split osteotomy: systematic review of fracture patterns. Int J Oral Maxillofac Surg 2016;45(7):887-97.

2 Wang T, Han JJ, Oh HK, Park HJ, Jung S, Park YJ, et al. Evaluation of Mandibular Anatomy Associated With Bad Splits in Sagittal Split Ramus Osteotomy of Mandible. J Craniofac Surg 2016;27(5):e500-4.

3 Trauner R, Obwegeser H. The surgical correction of mandibular prognathism and retrognathia with consideration of genioplasty. I. Surgical procedures to correct mandibular prognathism and reshaping of the chin. Oral Surg Oral Med Oral Pathol 1957;10(7):677-89; contd.

4 Hunsuck EE. A modified intraoral sagittal splitting technic for correction of mandibular prognathism. J Oral Surg 1968;26(4):250-3.

5 Dal Pont G. Retromolar osteotomy for the correction of prognathism. J Oral Surg Anesth Hosp Dent Serv 1961;19:42-7.

6 Epker BN. Modifications in the sagittal osteotomy of the mandible. J Oral Surg 1977;35(2):157-9.

7 Aarabi M, Tabrizi R, Hekmat M, Shahidi S, Puzesh A. Relationship between mandibular anatomy and the occurrence of a bad split upon sagittal split osteotomy. J Oral Maxillofac Surg 2014;72(12):2508-13. 
8 Camargo IB, Van Sickels JE, Curtis WJ. Simultaneous Removal of Third Molars During a Sagittal Split Does Not Increase the Incidence of Bad Splits in Patients Aged 30 Years or Older. $J$ Oral Maxillofac Surg 2015;73(7):1350-9.

9 Mensink G, Verweij JP, Frank MD, Eelco Bergsma J, Richard van Merkesteyn JP. Bad split during bilateral sagittal split osteotomy of the mandible with separators: a retrospective study of 427 patients. $\mathrm{Br} \quad \mathrm{J}$ Oral Maxillofac Surg 2013;51(6):525-9.

10 Verweij JP, Houppermans PN, Gooris P, Mensink G, van Merkesteyn JP. Risk factors for common complications associated with bilateral sagittal split osteotomy: A literature review and metaanalysis. $J \quad$ Craniomaxillofac Surg 2016;44(9):1170-80.

11 Kriwalsky MS, Maurer P, Veras RB, Eckert AW, Schubert J. Risk factors for a bad split during sagittal split osteotomy. Br J Oral Maxillofac Surg 2008;46(3):177-9.

12 Verweij JP, Mensink G, Fiocco $M$, van Merkesteyn JPR. Presence of mandibular third molars during bilateral sagittal split osteotomy increases the possibility of bad split but not the risk of other post-operative complications. $J$ Craniomaxillofac Surg 2014;42(7):e359-e63.

13 Chrcanovic BR, Freire-Maia B. Risk factors and prevention of bad splits during sagittal split osteotomy. Oral Maxillofac Surg 2012;16(1):1927.

14 Juodzbalys G, Daugela P. Mandibular third molar impaction: review of literature and a proposal of a classification. J Oral Maxillofac Res 2013;4(2):e1.

15 Eshghpour M, Nezadi A, Moradi A, Shamsabadi RM, Rezaei NM, Nejat A. Pattern of mandibular third molar impaction: A cross-sectional study in northeast of Iran. Niger $J$ Clin Pract 2014;17(6):673-7.

16 Camargo IB, Van Sickels JE, Cunningham LL. Simultaneous removal of third molars and completion of a sagittal split osteotomy: effects of age and presence of third molars. Oral Surg Oral Med Oral Pathol Oral Radiol 2016;121(5):46873.

17 Mehra P, Castro V, Freitas RZ, Wolford LM. Complications of the mandibular sagittal split ramus osteotomy associated with the presence or absence of third molars. J Oral Maxillofac Surg 2001;59(8):854-8; discussion 9.

18 Choi BJ, Park S, Lee DW, Ohe JY, Kwon YD. Effect of lower third molars on the incidence of mandibular angle and condylar fractures. $J$ Craniofac Surg 2011;22(4):1521-5.

19 Safdar N, Meechan J. Relationship between fractures of the mandibular angle and the presence and state of eruption of the lower third molar. Oral Surg Oral Med Oral Pathol Oral Radiol Endod 1995;79(6):680-4.

20 Reyneke JP, Tsakiris P, Becker P. Age as a factor in the complication rate after removal of unerupted/impacted third molars at the time of mandibular sagittal split osteotomy. J Oral Maxillofac Surg 2002;60(6):654-9.

21 Doucet JC, Morrison AD, Davis BR, Robertson CG, Goodday R, Precious DS. Concomitant removal of mandibular third molars during sagittal split osteotomy minimizes neurosensory dysfunction. $J$ Oral Maxillofac Surg 2012;70(9):2153-63.

22 Panula K, Finne K, Oikarinen K. Incidence of complications and problems related to orthognathic surgery: a review of 655 patients. $J$ Oral Maxillofac Surg 2001;59(10):1128-36; discussion 37.

23 Borstlap WA, Stoelinga PJ, Hoppenreijs TJ, van't Hof MA. Stabilisation of sagittal split advancement osteotomies with miniplates: a prospective, multicentre study with two-year follow-up. Part I. Clinical parameters. Int J Oral Maxillofac Surg 2004;33(5):433-41. 